\title{
Los desafíos de una nueva ciudadanía pampeana. Consecuencias de la implementación de la Asignación Universal por Hijo (2009-2015).
}

The challenges of a new pampean citizenship and the outcomes of implementing the Universal Allowance per Child (2009-2015).

Nahuel Currá

Ciencia Política (UBA)

Diplomado Superior

en "Gestión y Control de Políticas.

Públicas" (FLACSO);

Maestrando en "Políticas Sociales

Urbanas" (UNTRE

Nahuel.curra@gmail.com

14.10.16

Fecha de aceptación:

30.3.17

\section{Resumen}

En los últimos años el gobierno argentino implementó políticas sociales que lograron disminuir sustancialmente los niveles de pobreza e indigencia; al mismo tiempo persisten fuertes debates sobre si estas políticas han modificado o no la estructura preexistente de protección social. Como un aporte a esas discusiones el presente artículo busca identificar si la implementación de la Asignación Universal por Hijo (AUH) ha contribuido a regenerar el esquema de protección social asociado al modelo de seguro social vigente durante el formato institucional conocido como "Estado Benefactor", reconfigurando una nueva ciudadanía social que aquí denominamos pampeana, basándonos en el concepto de ciudadanía plebeya de Carlos Franco. En primer lugar se repasarán debates y discusiones sobre el concepto de ciudadanía, luego abordaremos brevemente cómo se manifestaron en Argentina los modelos de protección social y los procesos de ciudadanización. En tercer lugar nos abocaremos en las características de la AUH y tra- 
taremos de fundamentar la tesis que sostiene que la AUH generó las condiciones para la emergencia de una nueva ciudadanía que denominamos pampeana. Finalmente se presentan los resultados del trabajo y se esbozan posibles líneas de acción para generar políticas públicas que garanticen niveles de protección social más amplis.

Palabras clave: Neoliberalismo - Política Social - Asignación Universal por Hijo - Ciudadanía - Argentina.

\section{Abstract}

During recent years the Argentine government implemented a variety of social policies that have substantially reduced poverty and indigence. Yet there is an ongoing debate on whether they have in fact modified the structure of Argentina's social protection system. This article intends to contribute to this debate discussing to what extent the implementation of the Universal Allowance per Child (AUH) has involved changes in that system as well to the development of a new type of social citizenship that we brand as pampean citizenship, as a follow-up of Carlos Franco's plebeian citizenship. In a first section we review the main recent academic debates on the concept of citizenchip; subsequently we make a quick approach to the articulation of the different types of social protection and different processes of citizenship development in the recent past in Argentina. The third section as sesses the main features of $A U H$ and its contribution the enactment of a pampean citizenship. The final section sums up the main conclusions of our discussion.

Key Words: neoliberalism - social policy - Universal Allowance per Child - citizenship - Argentina.

\section{Introducción}

Luego de casi 30 años de aplicación de políticas económicas y sociales neoliberales en América Latina que llevaron a un incremento de la pobreza y una intensificación de la desigualdad social, en los últimos años se ha producido un proceso muy importante de reducción de la pobreza. Existen al respecto diversas discusiones y debates sobre si este descenso es producto de políticas públicas rupturistas con el modelo neoliberal o por el contrario es un signo de continuidad más que de cambio con ese modelo. Sea como fuere, un dato concreto es que, rupturistas o no, los estados latinoamericanos han implementado a lo largo de este período políticas públicas y en particular políticas sociales en pos de reducir el elevado nivel de pobreza que había alcanzado la región a fines de la década de 1990.

En Argentina, el desmantelamiento del Estado de Bienestar durante las décadas de 1980 y 1990 trajo aparejado el diseño y ejecución de políticas neoliberales que pusieron fin a la sociedad de pleno empleo generando las condiciones propicias para el incremento de la pobreza así como también de la intensificación de la desigualdad social ya existentes. Ante la realidad social producida por un modelo económico que generó un periodo de desindustrialización muy importante, el Estado aplicó políticas sociales focalizadas con el objetivo de contener socialmente a los sectores marginados, adhiriendo a la teoría según la cual el rol del estado es atender a los damnificados por el sistema económico hasta que el mercado pueda incluirlos nuevamente.

Este proceso tuvo su correlato a nivel mundial a partir del fin del arreglo o pacto socia entre el capital y el trabajo iniciado en la década de 1940, que dio lugar al denominado Estado de Bienestar. Dicho pacto permitía al capital obtener tasas de ganancias aceptables, así como la posibilidad de establecer una ciudadanía social que otorgaba beneficios sociales para amplios sectores de la población. Este esquema no eliminó las desigualdades sociales pero significó la instalación de lo que Carlos Franco (1996) denomina un sistema de "desigualdad socialmente aceptada". En América Latina y en nuestro país el pacto social que sostenía la ciudanía social y ese sistema aceptado de desigualdad se quebró en los años setenta impulsada por los sectores del capital y se conformó un nuevo pacto más favorable a ellos y por lo tanto un nuevo esquema de desigualdad social más perjudicial para los sectores populares.

Es importante señalar que tanto "Estado Benefactor" como "ciudadanía social" son conceptos eurocéntricos que no explican los procesos sociopolíticos latinoamericanos en plenitud. Sin embargo como este artículo se aboca a profundizar el análisis sobre los procesos de ciudadanización en nuestro país y el rol desempeñado en ellos por la Asignación Universal por Hijo (AUH), y a pesar de reconocer que calificar como "Estado Benefactor" o "Estado de Bienestar" al diseño político-institucional iniciado durante el peronismo y culminado en la década de 1970 implica una conceptualización 
cuanto menos simplificadora por lo anteriormente descripto, resulta práctico utilizarla para describir el período en el cual nuestro país experimentó en líneas generales un proceso de industrialización por sustitución de importaciones, pleno empleo y avances en conquistas de derechos laborales y sociales. Hecha esta aclaración podemos profundizar sobre el concepto que denominamos "ciudadanía pampeana".

El artículo busca aportar a las discusiones sobre la continuidad o no del régimen neoliberal en América Latina, aunque se centra en el caso argentino para desde ahí sumar a esos debates, sin ánimo de imponer una visión local a la región dada la diversidad de situaciones nacionales.

De manera preliminar definimos como ciudadanía pampeana un piso de protección social y calidad de vida para todos por igual en tanto ciudadanos, aceptada por el sector del trabajo y el del capital. Esta noción de lo aceptado por ambos sectores es lo que le da la particularidad a ese piso de protección, pues lo aceptado en Argentina no fue lo mismo que se aceptó en Europa o en otras regiones incluso de nuestro continente. El calificativo pampeano remite a una identificación del concepto de ciudadanía en ese período con una región de nuestro país, pero al mismo tiempo con un hecho de la realidad que radica en que la mayor parte de quienes definieron ese acuerdo, ya sea el sector del trabajo (formal) y del sector del capital se encontraba geográficamente situado en la zona del país más dinámica que era la región pampeana. Allí se concentraba la mayor parte de las inversiones privadas, estatales y asimismo una alta proporción de fuerza de trabajo.

Sostenemos que hacia fines de los noventa el pacto de desigualdad socialmente aceptada sufrió un nuevo quiebre que a diferencia de la década de 1970 fue producido por los sectores populares (el sector trabajo) que no toleraron más el proceso de incremento de pobreza y desigualdad existente junto con algunos sectores del capital perjudicados por el periodo neoliberal, reclamando un reacomodamiento de variables socioeconómicas. El fin del arreglo social neoliberal en Argentina explicó el fuerte descenso de los índices de pobreza así como también la más leve caída de la desigualdad. ${ }^{1}$

Sin embargo esta nueva situación pareciera no haber cambiado las condiciones estructurales del régimen neoliberal, ya que, a pesar de los avances señalados, persisten ciertas características del tipo de sociedad que emergió a partir de la crisis del Estado Benefactor. En este sentido, si bien se sostiene que se han profundizado las políticas sociales dirigidas hacia los sectores populares, que se han intensificados programas de transferencia condicionada de ingresos y aumentó sostenidamente el empleo, no se observa una ruptura total con la matriz neoliberal y todo indicaría que la crisis del arreglo social neoliberal aún persiste y por el momento no se logra edificar un nuevo arreglo. Sin embargo consideramos que hubo una política social que produjo un quiebre con la lógica neoliberal abriendo la puerta para la disputa por un nuevo arreglo social basado en una posición más favorable para los sectores populares. La AUH, impulsada por el gobierno nacional desde 2009 es un elemento troncal de esa apertura.

La hipótesis central de este artículo plantea que la AUH no solo permitió disminuir la pobreza, la desigualdad en la distribución del ingreso entre el capital y el trabajo y la desigualdad en el par categorial trabajo, ${ }^{2}$ sino fundamentalmente persiguió regenerar desde el Estado la ciudadanía pampeana desarrollada por el Estado Benefactor en Argentina. En otras palabras, trató de recrear las condiciones de protección social vinculada al trabajo registrado que primaron entre las décadas de 1940 y 1970, y que permitieron el surgimiento de esa ciudadanía. Ante el elevado nivel de informalidad persistente en el mercado de trabajo, el Estado no se quedó aguardando a que el capital o el modelo económico generara las condiciones para que el empleo registrado aumentara, sino que por el contrario adoptó una posición proactiva y expandió las asignaciones familiares a los trabajadores informales y desocupados dando el puntapié inicial a la promoción de un cambio estructural que sustentara una nueva ciudadanía pampeana. En este sentido se argumenta que la AUH puede ser vista como un principio de ruptura con las políticas sociales neoliberales y de reformulación del sistema de desigualdades aceptadas, más favorable s los sectores populares.

Aunque existen trabajos importantes que abordan las consecuencias de la AUH sobre las políticas sociales neoliberales, ${ }^{3}$ no hay muchos que aborden los cambios que esto generó en el concepto de ciudadanía.

\section{Democracia y desigualdad}

\section{"Arreglo social"}

Las sociedades modernas tienen la características de presentar una tensión constitutiva entre la existencia de un orden económico fundado en la apropiación desigual del excedente económico producido y la existencia de un orden político basado en un principio igualitario, para ser más preciso una tensión entre el principio igualitarista de la democracia representativa que presupone la igualdad política de todos los hombres y mujeres y el principio de la desigualdad vigente en el mercado capitalista. La forma de conciliar estos dos principios en conflicto constante, fue construir un tercer principio que Carlos Franco denomina el principio de la "desigualdad socialmente aceptada", que "implica (1) limitar cualquier tamaño de la desigualdad generada por el orden productivo y el mercado que sea incompatible con la gestión política de conflictos; (2) extender, con los recursos proveídos por el capital y el mercado, todos los derechos de ciudadanía que no pongan en cuestión las garantías básicas a la propiedad del capital y el funcionamiento del mercado" (Franco, 1996). 
De esta enunciación de Franco surgen importantes derivaciones: ante todo, la inclusión de la subjetividad como un aspecto central pues no solo contiene la objetividad de la propiedad de capital y la desigualdad material sino que a su vez introduce la subjetividad de lo que los actores del trabajo y del capital consideran la desigualdad tolerable o aceptable. Para ser más claro, la gestión de conflictos sociales que pueda generar la magnitud de una desigualdad material entre el trabajo y el capital puede variar diacrónica y sincrónicamente, pues por ejemplo la desigualdad aceptada en un país africano puede ser inaceptable en otro país al mismo tiempo, y a su vez la desigualdad aceptada hoy en día en Argentina tal vez no lo sea en 20 años. Lo mismo sucede con lo que el mercado considera como su tasa de ganancia razonable o legítima, eso también tiene un componente de subjetividad. Por lo tanto este campo se convierte en un espacio de disputa de poder entre el sector del trabajo y el capital, un espacio en constante tensión por la apropiación de lo que conceptualmente es considerado justo y lo que no lo es, pues eso implica luego consecuencias en el ámbito material. En definitiva lo que es justo está determinado por condiciones objetivas y subjetivas; al mismo tiempo que se condicionan mutuamente, siempre es una relación tensa y conflictiva. Sin embargo si bien este espacio de constante disputa es más dinámico que estático, es posible identificar a lo largo del tiempo un acuerdo entre lo que es considerado justo por parte del trabajo y del capital; a esto refiere Franco con el concepto de desigualdad socialmente aceptada, un acuerdo sobre lo que es socialmente justo y lo que no lo es, un acuerdo entre las partes que se da en diferentes momentos históricos y que nosotros llamamos "arreglo social".

\section{Ciclo vital de los "arreglos sociales"}

Al estar condicionados por variables objetivas y subjetivas, los arreglos sociales pueden modificarse a lo largo del tiempo. En su estudio del caso peruano, Carlos Franco describe el proceso de quiebre de un "arreglo social" como aquel que permite, luego de un período de crisis, generar un nuevo reacomodamiento entre las variables objetivas y subjetivas que constituyen una nueva desigualdad socialmente aceptada. Esta crisis se explica "por la ruptura de los patrones de reproducción material y de desigualdad socialmente aceptada" (Franco, 1997). Sin embargo; la ruptura de la "desigualdad socialmente aceptada no se explica por la extensión y la profundización de la desigualdad social (tal como esta se objetiva en la distribución del ingreso) sino más bien por la interpretación que de esta situación realiza la ideología de derechos y oportunidades que definen la identidad de los actores urbano-populares" (Franco, 1997). Cuando eso sucede se produce el quiebre y con el tiempo se forja un nuevo arreglo que siempre trae ganadores y perdedores: a veces serán los sectores relacionados al trabajo, otras al capital. De esta manera todo "arreglo social", al tener un patrón de reproducción material y un criterio determinado de desigualdad socialmente aceptada, varía según factores materiales objetivos e interpretaciones subjetivas sobre esa materialidad, imprimiéndole una singularidad determinada a cada caso. Esto explica las dificultades de trasladar arbitrariamente conceptos de un país a otro. ${ }^{4}$ Esas dificultades al trasladar las concepciones europeas sobre ciudadanía social no evitaron definir al arreglo social peruano, que en la interpretación de Franco dio sustento a una nueva ciudadanía - la "ciudadanía plebeya"- que no es ni más ni menos que "una ideología de derechos y oportunidades, un sistema valorativo que no solo direcciona las aspiraciones y los comportamiento sociales ante el estado y el régimen sino que define las expectativas ante su funcionamiento" (Franco, 1997). De esta manera la potencia y el gran aporte del concepto "ciudadanía plebeya" para este artículo, es básicamente comprender por un lado que el arreglo social, que las desigualdades que acepta una sociedad en un momento histórico también tienen que ver con una cuestión territorial, material y cultural que le dan una particularidad, e inmediatamente como consecuencia de ello que las políticas públicas que garantizaron ciertos mecanismos de protección social más generalizados también están condicionados por las características locales de cada lugar.

\section{Arreglo social y ciudadanía}

Hemos resaltado la importancia que tienen en la definición de un "arreglo social" los factores subjetivos y los objetivos, y su condicionamiento recíproco. En este sentido así como el contexto histórico y los modelos económicos son factores que condicionan a los posibles tipos de arreglo social, estos últimos también condicionan la existencia de diferentes tipos de ciudadanía. En otras palabras así como todo modelo económico y social estructura un tipo de arreglo social, este último conlleva un tipo de ciudadanía determinado. Ahora bien: del mismo modo que los arreglos sociales no son iguales diacrónica y sincrónicamente, tampoco lo son los tipos de ciudadanía que emanan de dichos arreglos. Es por ello que conceptos como la ciudadanía social marshalliana no suelen ser pertinentes para comprender los procesos sociopolíticos en Sudamérica, básicamente porque ni el Estado Benefactor ni la ciudadanía social se desarrollaron de manera similar a las de Europa, por la simple razón de que los estados, las sociedades, los mercados y las nociones de ciudadanía latinoamericanos mantienen sustanciales diferencias objetivas y subjetivas con las europeas en su condición y en su relación entre ellas. El corolario de estas especificidades latinoamericanas es la poca pertinencia del concepto marshalliano de ciudadanía social para analizar los procesos que tienen lugar en nuestro continente.

\section{"Ciudadanía"}

Como planteamos anteriormente, la ciudadanía es parte constitutiva de todo arreglo social y en consecuencia relevante para la comprensión de los efectos de un arreglo social en la sociedad en cuestión.

La definición de ciudadanía más conocida académicamente es la de T.H. Marshall: "un status que se otorga a los que son miembros de pleno de derecho de una comunidad...iguales en lo que se refiere a derechos y deberes que implica" (Marshall en Pérez Ledesma, 1998). Basándose en los aportes de Tocqueville sobre los tres escalones que hay que superar para alcanzar autentica igualdad, Marshall formuló las conocidas tres fases que 
hay que superar para establecer la plena ciudadanía, a saber la ciudadanía lesal relativa a los derechos civiles (derecho de propiedad, libertad de expresión, libertad a la persona, etc.), la ciudadanía política, relacionada con los derechos políticos (derecho a sufragio, a ocupación de cargos públicos) y finalmente la ciudadanía social que incluye el derecho a un mínimo de bienestar y seguridad económica. De esta manera la ciudadanía social se convertía en la coronación de la ciudadanía plena al contener las dos anteriores. Sin embargo consideramos que esta definición es demasiada estandarizada, homogénea y con un sesgo evolucionista que no resulta acorde para poder analizar nuestra región y particularmente nuestro país.

Principalmente identificamos tres grandes cuestionamientos a estos postulados: por un lado el carácter eurocéntrico de esta definición que no es de utilidad para analizar otras regiones e incluso como veremos a continuación tampoco lo es para incluso otros páses europeos; en segundo lugar la rigidez evolucionista y la caracterización de etapas que plantea la definición; finalmente la que calificamos como visión estática o naturalista de la ciudadanía, en cuanto no se la visualiza como un espacio de disputa política sobre su definición e implicancia.

\section{Críticas al eurocentrismo y el evolucionismo}

Se ha señalado incluso la no pertinencia de la aplicación de la concepción de Marshall para otros países europeos al considerar que sus postulados poseían un fuerte contenido de anglocentrismo. A continuación repasamos brevemente las principales críticas relacionadas al eurocentrismo y el evolucionismo de la definición marshalliana.

\section{El Anglocentrismo de la Ciudadanía Socia}

Según Pérez Ledesma "es evidente, y de ahí los ataques al anglocentrismo, que el esquema no se puede aplicar a otros estados europeos, en los que no se encuentra una secuencia evolutiva similar a la británica” (Pérez Ledesma, 1998). Es decir este autor también plantea observaciones a la lógica de etapas que no es acorde a la historia europea. Pérez Ledesma argumenta que esta secuencia de los tipos de ciudadanía pudo haber sido una descripción vaga de la experiencia británica; “ahora bien, no parece que ni en el Reino Unido, ni en el resto de los Estados Europeos la secuencia se produjera de esa forma, por lo que la correlación entre derechos políticos y sociales establecida por Marshall no resulta convincente" (Pérez Ledesma, 1998). A modo de ejemplo, en el imperio alemán y en Austria la conquista de muchos derechos sociales fue previa a la conquista de ciudadanía política; incluso en la misma Alemania de Bismarck a fines del siglo XIX el avance de derechos relacionados a la protección social era evidente (accidentes, vejez, desempleo). En 1911 en Gran Bretaña la sanción de la "insurance Act" de Lloyd George impulsó el seguro por enfermedad y desempleo, prefigurando lo que Marshall llamo ciudadanía social, con anterioridad a la consecución plena de la ciudadanía política. Otro de los ejemplos de estas incompatibilidades con la secuencialidad marshalliana la podemos encontrar en el período de 1890-1914, en el que mientras en Francia los derechos políticos estaban muchos más extendidos que en Gran Bretaña, sucedía lo contrario en los derechos sociales.

Según lo anterior se observa la discordancia en el orden evolutivo de dichos conceptos según cada país europeo, y no una lógica de pasos tan marcados como lo plantea Marshall; por el contrario se ve mucho más un entrecruzamiento en la conquista de derechos civiles, sociales y políticos, es decir, algunos derechos políticos y sociales se dieron al mismo tiempo, y otros no; en algunos casos derechos políticos conquistados fueron perdidos, o surgieron derechos sociales en momentos con derechos políticos clausurados. Lo esencial que se observa a partir del análisis de Pérez Ledesma es que el proceso de conquista de ciudadanía plena parece demostrar que lejos de ser un proceso prolijo y ordenado, se caracteriza el desorden y desprolijidad que reina en todos los procesos de lucha por la conquista de nuevos derechos.

\section{La versión Norteamericana}

La versión marshalliana de la ciudadanía social como momento culminante de la ciudadanía tampoco se ubica del todo bien en la experiencia norteamericana, donde todos los posibles beneficios sociales requerían de una contribución/contraprestación por parte del beneficiario. Esta manera de entender lo social traía como contrapartida que toda redistribución hacia sectores más desfavorecidos por parte del Estado fuera asociado a la caridad y no a un derecho, en tanto era algo que se le daba a un ciudadano que no podía aportar a ese sistema por falta de recursos (Fraser \& Gordon, 1992).

\section{Ciudadanía Plebeya, Corporativa}

A Carlos Franco no le parece difícil "advertir que la noción de ciudadanía de Marshal responde a una pauta histórica, acaso más inglesa que europea" (Franco, 1997); por lo tanto plantea objeciones y reparos al concepto marshalliano con base en la experiencia peruana. La secuencia de las tres etapas no resulta pertinente en Perú, la secuencialidad parece invertirse con respecto a Inglaterra. Muchos derechos sociales conquistados fueron reconocidos antes que se reconociera el derecho al voto a los analfabetas y a los jóvenes de 18 a 21 años, por lo tanto aquí "se incumple...la afirmación de Marshall según la cual el método universal de obtener derechos sociales se constituye en el uso de los derechos políticos".

Hay que destacar dos cuestiones relevantes de la crítica de Franco: por un lado, en Perú el Estado fue el propulsor de los derechos sociales más que los partidos políticos, y lo hizo bajo un gobierno autoritario en lo político y democratizador en lo social, ${ }^{5}$ por lo tanto la ciudadanía social fue previa a la política rompiendo la secuencialidad marshalliana. Por otro lado, el proceso de constitución de ciudadanía se realizó contra las pautas del orden imperante, es por ello que mientras Marshall plantea la "constitución 
de ciudadanía como un proceso de ampliación de derechos otorgados por las clases altas...dicho proceso en Perú toma la forma de una conquista de derechos desde abajo" (Franco 1997). En este sentido la diferencia sustancial que observa es que la constitución de ciudadanía es inconmensurable entre ambos casos; los derechos sociales y las organizaciones sociales cumplen en Perú, de acuerdo a este autor, el rol que Marshall asigna a la ciudadanía civil y al individuo en la constitución de la ciudadanía social.

Las incompatibilidades señaladas del concepto de ciudadanía social para nuestro continente también son planteadas por García Linera en su libro La potencia plebeya (García Linera, 2015), donde aborda la constitución de la ciudadanía en el caso boliviano. En dicho país la revolución obrera y campesina de 1952 fue el puntapié inicial de reformas tendientes a mejorar las condiciones de vida de la población; consagró conquistas sociales e implantó el voto universal. De esta manera en el caso boliviano tampoco el modelo de escalas secuenciales resulta oportuno: no existió una lógica evolutiva sino, por el contrario, la ciudadanía social y política, en el sentido marchalliano, fueron procesos que se dieron al mismo tiempo. Sin embargo García Linera hace un aporte más profundo que simplemente marcar este proceso de incompatibilidad secuencial, en cuanto se centra mucho más en lo que es la sustancia, lo constitutivo de la ciudadanía porque en definitiva "aunque la ciudadanía evoca a un conjunto de derechos políticos reglamentados y ejercidos por los individuos (ciudadanos)....su sustancia no es una ley, un decreto... ley y sanción solo regentan la sustancia social producida en lugares...como...la rebelión" (García Linera, 2015). De esta manera introduce algo novedoso a esta disputa sobre el concepto de ciudadanía que es complementar a la discusión sobre categorías más legalistas y secuenciales (derechos contenidos en cada tipo de ciudadanía y en qué orden se aplicaron) para sumar discusiones de cómo se llega a esa legalidad que en definitiva es la expresión material de esa ciudadanía y discutir la sustancia que es lo constitutivo de la ciudadanía y de esta manera poder abordar de manera acabada este concepto

\section{Visión Estática y Natural de la Ciudadania Marshalliana}

A la hora de evaluar la ciudadanía marshalliana nuestra mayor preocupación no gira solo en torno a las incompatibilidades de trasladar el concepto de Marshall a otros países, descriptas anteriormente, es decir no nos preocupa solo demostrar que el carácter evolutivo de la secuencialidad marshalliano no es útil para entender nuestras realidades sino lo que más nos interesa es resaltar que la forma de construcción de ciudadanía marshalliana no nos parece correcta. Si bien Marshall define a la ciudadanía como un "proceso histórico-cultural a través del cual se genera un conjunto de valores, creencias e ideales que definen la igualdad humana básica" y de esta manera le impone una impronta política al entender esa construcción como un proceso social donde se definen de diferente maneras la igualdad humana, termina naturalizando su definición cuando su análisis coloca mucho más peso en las categorías relacionadas con la secuencia temporal y los derechos que implica cada etapa. De esta manera entiende al concepto de ciudadanía como parte de un proceso histórico cultural que genera valores determinados sobre la igualdad como algo que está concluido y obturado. Es decir considera a la ciudadanía como una enumeración de derechos, con tales características que se despliegan en un orden determinado. Sin embargo creemos que ese proceso histórico continúa permanentemente y nunca se salda; es por eso que el concepto de ciudadanía es un concepto político porque está en constante cambio y movimiento, su contenido está en disputa siempre y esto no se ve reflejado en la caracterización de Marshall.

Por otro lado acordamos con Franco que para Marshall la constitución de ciudadanía es un proceso otorgado desde los sectores altos y desde el Estado; es decir Marshall proyecta una imagen de derechos adquiridos por voluntad del Estado luego de un proceso histórico, cuando en realidad nosotros consideramos que el proceso de constitución de ciudadanía emana desde las luchas de los sectores populares y el Estado es quien cristaliza esas demandas, las hace ley, pero su sustentabilidad radica en las luchas populares. Esto da contenido político al concepto de ciudadanía; en tanto producto de luchas populares, será siempre algo en permanente cambio. Los procesos históricos son producto de vaivenes, de luchas que reflejan en diferentes momentos diferentes cristalizaciones de esa realidad. Este señalamiento es muy importante porque Marshall se termina centrando en lo estatal y lo legal, cuando en realidad, como plantea García Linera, "el Estado es la síntesis expresiva de los procesos de ciudadanización que bullen en el interior de la estructura social” (García Linera, 2015, p. 174).

En sintonía con lo anteriormente señalado, debe retenerse que el contenido de la ciudadanía está en lo social; lo legal, lo institucional, son frutos de lo social, y lo social, cuando se instituye, se convierte en "lo político". De esta manera el Estado puede hacer muchas cosas, puede sancionar leyes, puede dar derechos, sin embargo "no puede inventar al ciudadano. Cuando lo hace...se extenderá al cuerpo político sin más receptividad que la indiferencia" (García Linera, 2015, p. 174). Por ello creemos que más allá de las dificultades de trasladar un concepto a realidades que no son aquellas a las que refiere su elaboración, creemos que más importante es no descuidar que detrás de cada derecho conseguido hay un conjunto de luchas, hay historia, hay política y cuando hay política jamás hay uniformidad porque lo político es sinónimo de cambio y transformación.

Luego de esta discusión podemos concluir que la ciudadanía social de Marshall es el corolario del arreglo social en que se asentó el Estado Benefactor a lo sumo en la Europa occidental (por no decir solo en Inglaterra) entre las décadas de 1940 y 1970. En otras palabras "según la formulación de Marshall, la ciudanía social es una respuesta estratégica al conflicto entre la tendencia democrática a la igualdad de derechos y el valor que otorga el capitalismo a la desigualdad: el problema consiste en que es necesario dar con una vía hacia una desigualdad legitimada que resulte viable políticamente" (Procacci, 1999). 
La ciudadanía social europea o británica se sostuvo bajo el paraguas del modelo de Estado de Bienestar y de políticas económicas llamadas keynesianas que fomentaron una sociedad centrada en el mundo del trabajo, con pleno empleo, elevados niveles de consumo y una intervención fuerte del estado garantizando servicios sociales como educación y salud de manera gratuita. Por otro lado tenemos claro que la ciudadanía social marshalliana, resulta de poca utilidad para entender los procesos sudamericanos. Finalmente y en base a las características de constitución de arreglos sociales y de los procesos de ciudadanización consideramos que la Argentina ha constituido su propia ciudadanía plebeya, que nosotros llamamos "ciudadanía pampeana". A continuación profundizaremos sobre el surgimiento, auge, caída de la ciudadanía pampeana así como trataremos de identificar el renacimiento de la misma en los últimos años.

\section{Arreglo social y ciudadanía en Argentina}

\section{La solución armada}

En Argentina también hemos tenido nuestra ciudadanía plebeya, pues nuestra condición de país periférico y las relaciones de poder imperantes impiden que una aplicación directa de los postulados de ciudadanía social como postula Marshall lleve a buen puerto. A nuestro criterio, en nuestro país podemos identificar rápidamente dos grandes momentos históricos: el primero se inició y dio sus primeros pasos con el fin del modelo agroexportador y el inicio del proceso de sustitución de importaciones y se terminó de consolidar con el advenimiento del peronismo, que en líneas generales edificó un modelo de pleno empleo, y un sistema de protección social asociado al mundo del trabajo, centrado bajo el conocido "enfoque de trabajo" (Soldano y Andrenacci, 2006) e históricamente asociado al modelo de Estado Benefactor europeo. Este esquema generó un nivel de cobertura social cuasi universal garantizando una ciudadanía pampeana altamente integradora que al mismo tiempo mantenía tasas de ganancias del capital tolerada por estos sectores.

De esta manera este modelo sostenía un esquema de protección social generalizado con base en un proceso de alta mercantilización de la fuerza del trabajo y una elevada desmercantilización de las necesidades (Danani 2009). Es decir, los beneficios sociales eran asociados a la condición de trabajador, generando una sociedad fuertemente integrada al proceso productivo, vinculando el éxito de este modelo de cobertura social al mantenimiento de un esquema de pleno empleo. A partir de la década de 1970 este arreglo social empezó a cuestionarse tanto a nivel mundial como en su correlato nacional. La pérdida de legitimidad de dicho arreglo se motorizó desde los sectores del capital, es decir la desigualdad socialmente aceptada por los diferentes sectores sociales comenzó a perder su legitimidad desde el sector del capital que consideró en aquel momento que sus tasas de ganancias, su nivel de apropiación de la renta del capital, en definitiva el funcionamiento del mercado, dejaron de ser suficientes y aceptables.

La situación de crisis del arreglo social intensificó la tensión entre democracia y ca- pitalismo y condujo a una "solución autoritaria". Las fuerzas armadas hicieron valer la correlación de fuerzas en favor de los intereses del capital instalando con base en la coacción medidas de liberalización de la economía, que sentarían las bases para que luego pudiera desplegarse el neoliberalismo en su plenitud. Fue a partir de las consecuencias sociales que rápidamente trajo aparejado este tipo de políticas económicas, que se pudo edificar un nuevo arreglo social basado en otra realidad material que había sido modificada por la fuerza, sepultando la ciudadanía pampeana y dando lugar a un nuevo arreglo social, que denominamos "arreglo social neoliberal". Es decir ante la ruptura de los patrones de reproducción material (Modelo semi-industrial) y de desigualdad socialmente aceptada la solución armada instauró un nuevo patrón de reproducción material (fin del modelo industrial) sobre el cual se edificó ya bajo el proceso democrático posterior un nuevo arreglo social sin lugar a dudas mucho más regresivo para el sector del trabajo, y que constituyó una nueva ciudadanía.

\section{"Arreglo social neoliberal"}

La aplicación del modelo neoliberal fue un proceso que si bien rápidamente modificó el patrón de reproducción material, continuó acentuando su desarrollo a lo largo de la década del ochenta y fundamentalmente en la del noventa. Este proceso de apertura de fronteras y extranjerización de la economía puso fin a la sociedad de pleno empleo asociada al mundo fabril. El cierre de fábricas que comenzó en la década del setenta se intensificó hasta la década del noventa inclusive. La reforma del Estado y el proceso privatizador de empresas, acelerados durante los gobiernos de Carlos Menem (1989-1999), contribuyeron a la generación de una sociedad profundamente desigual, ${ }^{6}$ con índices de desocupación e informalidad laboral que alcanzaron niveles históricos. Consecuencia de estos acontecimientos "desde la restauración democrática argentina en 1983 la pobreza comienza a ocupar un lugar central en la política pública social" (Cortes y Kessler 2013).

De esta manera al fenómeno de la informalidad laboral, que se acentuó en la década de 1980, se suma en la década siguiente la desocupación como eje de los problemas sociales. Es esta nueva realidad material producida por el neoliberalismo y fomentada por los sectores del capital la que permitió edificar un nuevo arreglo social bajo condiciones de desigualdad mucho peores para el sector del trabajo que en la década de 1970. En este punto se puede observar cómo el grado de desigualdad que es aceptada por una sociedad puede variar a lo largo del tiempo de acuerdo a dos aspectos: por un lado, uno de carácter objetivo, como es una nueva realidad económica; por el otro, algo subjetivo que tiene que ver con la interpretación que de esta situación (cómo esta objetivada en la realidad esa desigualdad) realiza la ideología de derechos y oportunidades que definen los actores en base a un sistema de valores y expectativas sobre lo que es aceptable.

Esta nueva realidad del país que estructuró el "arreglo neoliberal", dio mayor complejidad a la estructura social. Pérez Sainz y Mora Salas (2009) han aportado una muy 
buena conceptualización para comprender esa sociedad, en especial con la idea de la existencia de una división interna dentro del par categorial trabajo y capital, que dichos autores asocian al modelo previo al neoliberalismo. A nuestro criterio, en Argentina esa conceptualización es aplicable al periodo neoliberal: si en el periodo previo existían dos grandes sectores enfrentados (trabajo y capital), la aplicación del neoliberalismo sumó nuevos actores. El sector trabajo se fragmentó en tres fracciones. Además de la fractura preexistente entre trabajadores registrados (sector formal) y quienes se desenvolvían en el sector informal, apareció especialmente en la década de 1990, un tercer grupo, que Pérez Sainz y Mora Sala no identifican, producto de la desocupación: amplios sectores de la población que no solo no tenían trabajo registrado sino que tampoco encontraban empleo en el mercado informal.

Como parte del mismo proceso la apertura de las importaciones y el ingreso sin contro de capitales externos modificó las características del capital nacional. Por un lado, un sector de la burguesía industrial y comercial vinculada a las exportaciones de productos manufactureros se vio perjudicado, llevando a muchos de ellos a la quiebra. Por otro lado, otro sector del capital pudo reconvertir sus empresas reorientándolas hacia el comercio exterior, vendiendo productos importados en lugar de seguir produciéndolos. Asimismo el capital sumó un nuevo actor: las empresas transnacionales, que se convirtieron en un factor de peso y de influencia en la política económica argentina. De esta manera el capital también experimentó cambios profundos derivados de un proceso muy fuerte de concentración tanto en el sector trasnacional como en un sector de la burguesía nacional que dividió al sector del capital en dos grandes sectores, grandes grupos económicos y cada vez menos pequeñas y medianas empresas. En este sentido no solo se incrementó la desigualdad de posiciones entre el capital y el trabajo sino también hacia el interior del capital.

Durante esta etapa la pobreza fue tomada como algo individualizado negando así su carácter social (Procacci, 1999), generando respuestas particulares, focalizadas y no generales, pensándose más en las consecuencias de la pobreza que en sus causas e imponiéndose una noción de justicia centrada en la igualdad de oportunidades, que a diferencia de la igualdad de posiciones aspira "menos a reducir las desigualdades de posiciones sociales que a luchar contra las discriminaciones que obstaculizan la realización del mérito, permitiéndole a cada cual acceder a posiciones desiguales como resultado de una competencia equitativa" (Dubet, 2012).

Como parte de las estrategias de abordaje de la política social, con una lógica de individualización de la pobreza, las políticas sociales se orientaron a los conocidos Programas de Transferencias Condicionadas (PTC) que consistían en la traslación de recursos monetarios a sectores de la población focalizados por su condición de vulnerabilidad y pobreza a cambio de una contraprestación laboral, educativa o sanitaria. Estas políticas públicas cumplían un rol de contención y asistencialismo social que se basaban en una visión de la política social como algo transicional o como Vilas denomina "función bomberil" de las políticas sociales, actuando "en situaciones límite que puedan convertirse en focos de tensión política, alimentando la inestabilidad social..." (Vilas, 1997).

Las políticas neoliberales profundizaron la desigualdad no solo entre el capital y el trabajo sino dentro de cada par categorial. "Dentro del capital los grandes empresarios combinaban la explotación de su fuerza de trabajo...con el acaparamiento de rentas oligopólicas en el mercado en detrimento de los pequeños productores" (Pérez Sainz y Mora Salas, 2009), al mismo tiempo en el sector del trabajo "los asalariados formales...lograban erigir barreras para acaparar rentas con respecto a los sectores informales" (Pérez Sainz y Mora Salas, 2009); como las barreras que los sectores formales de la economía ponían al ingreso de los sectores informales al ámbito formal. Ejemplo de ello es el rol de los sindicatos quienes defendieron y defienden a sus trabajadores, y esta defensa sectorial, relega en un segundo plano la realidad de los sectores informales. En este sentido las barreras que imponían los sectores del trabajo y del capital hacia dentro de su categoría en pos de la apropiación del excedente no solo evitaban la disminución de brechas entre los distinto sectores sino que consolidaban aún más la nueva fotografia de fragmentación interna del par categorial de tres posiciones en el sector del trabajo (formal, informal y desocupados) y entre muy grandes y muy pequeños empresarios en el sector del capital, generando una enorme desigualdad de posiciones que, como plantea Dubet, termina perjudicando fuertemente cualquier tipo de igualdad de oportunidades porque mientras más grande sea la brecha más dificil es cualquier ascenso o movilidad social (Dubet, 2012).

\section{"Ciudadanía irresponsable"}

Al principio del artículo hemos explicado que todo modelo económico tiene de correlato un arreglo social determinado, así como todo arreglo social tiene como correlato un tipo de ciudadanía. De esta manera el surgimiento del modelo económico neoliberal en Argentina que puso fin al modelo de bienestar constituyó el "arreglo social neoliberal" y a su vez instituyó un nuevo tipo de ciudadanía que llamamos "ciudadanía irresponsable". El concepto de ciudadanía irresponsable lo hemos adoptado del trabajo de García Linera La Potencia Plebeya (García Linera, 2015), quien designa con ese nombre a la ciudadanía durante el período neoliberal.

En el esquema del Estado Benefactor el pleno empleo, el alto grado de formalidad laboral y las elevadas tasas de sindicalización constituyeron una ciudadanía activa y participativa no solo en el ámbito electoral sino también en las relaciones laborales. Los derechos adquiridos durante la vigencia de este esquema, fruto de luchas de los trabajadores reconocidas por el estado, estaban asociados al mundo del trabajo (asignaciones familiares, vacaciones pagas, obra social, etc.); de esta manera la "ciudadanía pampeana" se constituía en base a la condición de trabajador y a su vez como un actor colectivo importante para constituir nuevos derechos. 
En cambio en el arreglo social neoliberal, en un contexto social y económico totalmente distinto, la ciudadanía se estructuró en base al ciudadano votante, al ciudadano elector convirtiendo al ejercicio de la ciudadanía en ir a votar cada dos años, delegando en los dirigentes políticos el ejercicio de las decisiones. De esta manera esta práctica electoral sin su correlato de participación ciudadana en el ámbito sindical, social y barrial terminó convirtiendo al ejercicio electoral en un acto donde se "abdica voluntariamente de su decisión de gobernarse y de autorepresentarse como conglomerados colectivos...y que el voto exige el aplanamiento individualizado del electorado" (García Linera 2015). De esta manera la filiación de la ciudadanía pampeana basada en el ciudadano trabajador es reemplazada por la ciudadanía neoliberal que es configurada a partir del ciudadano elector, individual y aislado.

Podría decirse que mientras en la ciudadanía pampeana el ciudadano es parte de la constitución de esa ciudadanía, en tanto trabajador discute sobre sus condiciones laborales, participa de una sociedad activa y politizada, que instituye nuevos derechos a partir de las luchas que se van desplegando, la ciudadanía neoliberal se centra en e individuo aislado y votante, que se explica por las condiciones económicas que surgieron a partir de la década del ochenta y se consolidaron en los noventa. Este ciudadano neoliberal que delega la voluntad política ya que no participa más que en el ejercicio del voto, "presupone, por tanto, un tipo específico de sujeto, el sujeto delegante que no es responsable de sus actos porque es impotente frente a sus circunstancias" (García Linera, 2015, p. 190), de ahí su denominación de ciudadano irresponsable. Asimismo este ciudadano irresponsable al someterse a un acto institucional y ya normado como el voto termina siendo un individuo aislado que no participa en la constitución de nuevos derechos, siempre delega, nunca ejerce y por lo tanto delega también lo propio de "lo político" la creación de algo distinto y algo nuevo, esta ciudadanía es irresponsable pero al mismo tiempo sin darse cuenta esclava de la norma. Es menester aclarar que no se persigue en este argumento desvalorizar la participación electoral, sino por el contrario resaltar la importancia y necesidad de complementarla con participaciones en otros ámbitos como el social, sindical, barrial, etc.

\section{3. ¿El principio de un nuevo arreglo social? La Asignación Universal} Por Hijo (AUH) como búsqueda de una nueva ciudadanía pampeana

Críticas al Arreglo Social neoliberal, camino hacia "arreglo social universal"

Durante las décadas de 1980 y 1990 el arreglo social neoliberal fue desarmando todo el esquema productivo e institucional que estaba edificado bajo el modelo de Estado de Bienestar; las políticas sociales del período anterior comenzaron a resultar inadecuadas para este nuevo enfoque. En un país con altos niveles de informalidad laboral y desempleo la protección social basada en el trabajo formal resultaba insuficiente ya que muchas personas quedaban sin cobertura. En este contexto y ante la proliferación de los programas focalizados de transferencia condicionada de ingresos, surgieron discusiones sobre el ingreso ciudadano. De acuerdo a Barbeito y Lo Vuolo (2003) "La idea del «ingreso ciudadano" (IC), término con el cual se difundieron en el país los conceptos de «ingreso básico» o "«renta básica», no forma parte de la tradición en materia de políticas públicas". Según Repetto, la idea de la implementación del IC y de políticas públicas relacionadas con el enfoque de derechos se enfrentaban tanto a las políticas implementadas en el modelo de Estado de Bienestar que se apoyaba en los lineamientos del enfoque de trabajo basado en el régimen de seguridad social, así como también a las políticas sociales focalizadas del modelo instituido bajo el arreglo social neoliberal (Repetto 2010). En nuestro país los planteos del IC comenzaron a surgir a mediado de 1995 y el principal eje de preocupación en ese momento era instalarlo en la agenda académica y política, asimismo este "incipiente debate derivó a la consideración de la "viabilidad", especialmente, en cuanto al sustento político y a los límites que surgen de la restricción fiscal en un país con alto endeudamiento, prolongada depresión económica y débil administración tributaria" (Barbeito y Lo Vuolo, 2003). Por estas razones, se presumía remotas las posibilidades de aplicación de un IC pleno en el corto plazo, y de esta manera se comenzó a considerar la aplicación de variantes de IC de alcance parcial pero que, a la vez, tengan impactos inmediatos sobre los grupos más vulnerables.

Teniendo en cuenta lo anteriormente mencionado acontecieron dos instancias en la discusión del IC, la primera consistió en instalar la idea de un Ingreso Ciudadano de la Niñez fundamentado en que los niños eran los más afectados por la situación de pobreza acompañado de propuestas de financiamiento de dicho programa; posteriormente se incorporó un nuevo grupo poblacional a la discusión sobre el IC y se planteó como propuesta y reclamo la creación de un Ingreso Universal para adultos mayores.

El Ingreso Universal para la Niñez recibió el apoyo político del ARI, ${ }^{7}$ que presentó un proyecto parlamentario en 1997. La Central de Trabajadores Argentinos (CTA) también apoyó estas iniciativas y adhirió a los reclamos por un Ingreso Básico Ciudadano. De esta manera se sumó un nuevo tipo de demanda que reclamaba la sustitución de las políticas sociales neoliberales focalizadas un nuevo conjunto de políticas sociales de carácter universal que dieran cobertura básica a toda la población independientemente de su condición socio económica. La realidad es que no se pudo avanzar en la década del noventa en ninguna de estas medidas; la continuidad del arreglo social neoliberal y sus políticas sociales contribuyeron a la crisis que estaba en gestación y detonó a fines de 2001.

\section{Crisis del arreglo social neoliberal}

La crisis del 2001 implicó un momento bisagra para la Argentina, una vez más un arreglo social había entrado en crisis, tal vez sería más pertinente decir que el mismo entró en crisis años antes y en el 2001 terminó estallando por el aire. Sin embargo es importante resaltar que el colapso del arreglo social neoliberal y su sistema de desigualdades, 
no obedeció a la acción de los sectores del capital, como ocurrió con el de la década de 1970. El estallido de principios del nuevo milenio fue llevado adelante por los sectores del trabajo que no toleraron más la situación de crisis económica, social y política de aquel momento trágico de nuestro país. En ese momento se dio una situación particular, todo el movimiento del trabajo pudo lograr la unidad en base al descontento por la situación económica, desde los sectores desocupados (que superaban el 20\% de la población activa), los sectores informales e incluso los sectores formales sumamente afectados en aquel momento por los recortes salariales, leyes de flexibilización laboral e incluso por las consecuencias que muchos de ellos sufrieron por parte del corralito. En este sentido la crisis del 2001 no solo puso fin a un gobierno sino que también abrió las puertas a la disputa por un nuevo arreglo social y un nuevo modelo económico.

Luego de la caída del gobierno de Fernando De la Rúa, el nuevo presidente Eduardo Duhalde puso fin al régimen de convertibilidad e inició un proceso de apaciguamiento de las demandas populares. Una de las medidas que tomó para lograrlo fue el Plan Jefes y Jefas de Hogar Desocupados (PJJHD), que consistió en una transferencia de recursos a sectores desocupados, contando con más de 2 millones de beneficiarios. Asimismo la devaluación de la moneda si bien provocó una fuerte pérdida de poder de compra de los sectores del trabajo al mismo tiempo generó las condiciones de posibilidad para la política económica que habría de encarar el siguiente gobierno.

Con la asunción de Néstor Carlos Kirchner a la Presidencia de la República el 25 de mayo de 2003 se fortaleció el proceso de reindustrialización, se fomentó la producción nacional, se elevaron los niveles de protección, y se aplicaron políticas sociales redistributivas. En conjunto estas acciones explican la revalidación en las urnas con los triunfos electorales de Cristina Fernández de Kirchner en 2007 y 2011. No obstante ello, se reconoce la persistencia de los rasgos fundamentales de un arreglo social más parecidos al del periodo neoliberal que a la ciudadanía pampeana construida en los años cuarenta en especial en lo que refiere a los niveles de informalidad laboral y las consecuencia que esta genera en lo que hace al nivel de ingreso, y al sistema de protección social, etc. Sin embargo, la creación de la AUH puede interpretarse como el punto de partida para enfrentar este desafío.

\section{Asignación Universal por Hijo (AUH), semilla de la Ciudadanía Pampeana del Siglo XXI} A pesar de los avances en materia social durante el período 2003-2015 que permitieron reducir sustancialmente la tasa de desempleo, los niveles de informalidad laboral no han disminuido, manteniéndose en alrededor de un $35 \%$ en la actualidad. Esto confirma que si bien se han transferido cuantiosos recursos económicos hacia los sectores del trabajo no se ha podido modificar la estructura de la sociedad en lo que respecta a la situación de la informalidad laboral. Sin embargo, consideramos que la reducción del desempleo y en especial la instauración de la AUH ha sido fundamental para recrear las condiciones de posibilidad de una ciudadanía pampeana del siglo XXI porque ha dado cobertura social por igual a todo el sector del trabajo ya que ha extendido las asignaciones familiares de los trabajadores formales para los sectores informales y desocupados. Esto se encuentra plasmado en la legislación, pues la $\mathrm{AUH}$, que cuando fue sancionada por decreto fue integrada a la ley de asignaciones familiares, posteriormente fue sancionada por ley.

A nuestro criterio la AUH no es una política social más; la ciudadanía pampeana se forjó como un sistema de protección social atado al modelo de seguro social, que brindaba cobertura en virtud de la condición de trabajador. Este modelo, que garantizó una cobertura amplísima y altos niveles de igualdad entre los trabajadores fue muy exitoso cuando en nuestro país persistía una estructura productiva de pleno empleo. Sin embargo ante el aumento de la informalidad resultó por lo menos disfuncional ampliando incluso las desigualdades entre los trabajadores, ya que los trabajadores formales recibían todos los beneficios y protección social del Estado, mientras que los sectores informales que más necesitaban de dicho acompañamiento quedaban relegados en la búsqueda de programas o planes sociales, asociando a estos grupos a la "lógica de caridad" (Fraser \& Gordon, 1992). En este sentido la AUH vino a reparar la situación de sectores muy abandonados y a disminuir fuertemente la brecha de desigualdad dentro del par categorial trabajo, ya que dotó a los sectores informales de un ingreso que percibían los sectores formales por su condición de trabajador. Asimismo lo que es aún más importante es que ha reconocido desde el Estado a los sectores informales como trabajadores con los mismos derechos que los trabajadores formales (al menos con respecto a la niñez) y de esta manera ha abierto la puerta de la nueva lucha por recrear una nueva ciudadanía pampeana, ya no solamente desde el Estado sino sobre la reconstrucción de esa ciudadanía también desde el mercado, y este es a nuestro criterio el desafio de este tiempo. Esto quiere decir ni más ni menos generar las condiciones materiales en el mercado propicias para generar una fuerte disminución del trabajo informal para que realmente no solo estos sectores perciban el ingreso por la niñez como ya lo están haciendo sino que tengan garantizado obra social, aportes jubilatorios, paritarias, convenios colectivos, protección sindical y demás derechos y conquistas que generarían una muy fuerte disminución de la desigualdad social tanto dentro como fuera dentro del par categorial trabajo.

AUH en camino a una "Ciudadanía Universal" o a una "Nueva Ciudadanía Pampeana" El trabajo de Barbeito y Lo Vuolo sobre el "Ingreso Ciudadano" (Barbeito y Lo Vuolo, 2003) describe el devenir histórico en nuestro país de las propuestas y de las políticas asociadas al enfoque de derechos de las políticas sociales, y pone otro foco de tensión y debate sobre el rol que juega la AUH. No solamente está la tensión seguridad social - asistencia (Hintze, 2015), es decir la tensión sobre si la AUH inicia una ruptura con el arreglo social neoliberal configurando una política social que se perfila de acuerdo al modelo de enfoque de trabajo y abriendo el camino a la institución de una nueva ciudadanía pampeana, sino que ahora se suma a aquellos que observan a la AUH como una medida que puede 
romper con el arreglo social neoliberal pero en dirección hacia un enfoque de derechos buscando perfilar una nueva ciudadanía, que podríamos llamar universal. La pretensión de validez de esta última postura se basa en las dos instancias que atravesó la discusión del IC en nuestro país que se habían planteado a mediados de los años noventa por los sectores propulsores de la implementación del IC través de la creación de un ingreso a la niñez y a la vejez. Sin embargo nosotros creemos que la AUH no persigue el camino de la creación de un ingreso universal por la simple condición de ciudadano como son los planteos de los adherentes del enfoque de derechos; la realidad es que la AUH fue creada como una forma de extensión de los salarios familiares hacia los trabajadores informales tratando de recrear la protección social que primó durante el enfoque de trabajo en un contexto diferente. Es así como a medida que la AUH fue avanzando, lo hizo sumando derechos contenidos en las asignaciones familiares formales: ingreso por embarazo, kit escolar, etc.

Por otro lado las moratorias jubilatorias iniciadas durante la presidencia de Néstor Kirchner y continuadas durante la de Cristina Fernández de Kirchner, también podrían ser consideradas como la propuesta del ingreso por vejez; sin embargo pensamos que este caso también sigue la lógica anteriormente planteada. El ingreso por vejez (Moratoria) y por niñez (AUH) son otorgados en función de dos variables, en el caso de los ancianos en base a la suposición de que todos estos años han trabajado y no han hecho aportes por ser parte del mercado informal o porque las condiciones del mercado o incluso cuestiones de género (rol de la mujer como ama de casa) los han excluido de la posibilidad de conseguir un trabajo remunerado; en el caso de la AUH en función de la suposición de que ese padre/madre está trabajando en el mercado informal o si no lo está haciendo es por responsabilidad del Estado, porque este es quien tiene la obligación de generar las condiciones para que el país tenga pleno empleo en la convicción de que este es el mecanismo real de inclusión social. Puede parecer que las políticas sociales que se ejecutan se acercan a un enfoque de derechos; esta confusión parte de no comprender que el objetivo que se planteó estos años por el gobierno anterior fue el acceso al trabajo y que de ahí se desprendan los beneficios sociales. Insistimos que en estos últimos 12 años se buscó regenerar el enfoque de trabajo, mercantilizando la fuerza de trabajo y desmercantilizando las necesidades; creer que el camino seguido estos últimos años conduce a un enfoque de derechos que desmercantiliza la fuerza de trabajo y las necesidades al mismo tiempo (Danani, 2009) es a nuestro criterio un error.

\section{Desafios y obstáculos en la consolidación de la Ciudadanía Pampeana}

El desafio que hay por delante es desarrollar las condiciones en el mercado para alcanzar el pleno empleo formal. Sin embargo nuestra preocupación es que pareciese que actualmente ya estaría consolidado un nuevo arreglo social, que hemos encontrado un nuevo punto de equilibrio de las desigualdades socialmente aceptadas que no incentivan a mayores modificaciones estructurales. Esto se ve reflejado en la enorme legitimidad que tiene la $\mathrm{AUH}$ en los sectores políticos y sociales y lo poco que se habla de cómo avanzar más allá ella. Es importante reiterar, con base en el trabajo de Carlos Franco, que para constituir un "arreglo social" no es tan importante el nivel de desigualdades en su expresión material sino la interpretación que los diferentes sectores de la sociedad hagan al respecto. Debemos estar atentos a los desafios que esto implica a la hora de pensar la reconstrucción de la ciudadanía pampeana, porque persisten fuertes resistencias de parte de la sociedad a esta interpretación. De hecho muchos sectores del trabajo formal tienen fuertes reticencias respecto de los sectores que perciben la $\mathrm{AUH}$, calificando a esta medida estatal como un "plan para vagos" o resaltando que induce a que las mujeres tengan más hijos para poder cobrar más ingresos, ignorando totalmente que el estado argentino paga a todos los trabajadores formales un ingreso extra por cada hijo o hija que se denomina salario familiar. Por otro lado la cobertura para los niños de los trabajadores también alcanza a aquellos afectados por el impuesto a las ganancias quien si bien no cobran el salario familiar puede deducir a sus hijos del pago de dicho impuesto.

Sin lugar a dudas el sector del capital no va a aceptar pacíficamente que se avance en este sentido. Hay en la Argentina e incluso en la región signos de que el sector del capital ha empezado a endurecer sus posturas frente a los avances del Estado sobre políticas redistributivas; en ese sentido se trata de algo que se registra a lo largo de la historia entre los sectores del capital y el trabajo. Nosotros creemos que defender los objetivos de la AUH no es más ni menos que propiciar su propia desaparición, pues el sentido final de esta medida sustancial junto con la otra importante medida -la moratoria de jubilaciones- busca volver a generar un esquema de pleno empleo "formal"; cuando eso suceda la AUH se va a convertir en Asignación Familiar. Por lo tanto creemos que la propia creación de la medida nos debe interpelar a su superación y muchas veces pareciese (tal vez hasta involuntariamente y con buenas intenciones) que la AUH es un derecho per se cuando en realidad debe ser el empleo formal el derecho per se para todos los argentinos.

\section{Conclusiones}

A lo largo del artículo hemos tratado de contribuir a las discusiones sobre los avances y las limitaciones de las transformaciones realizadas en estos últimos años en materia de igualdad y desigualdad social pero fundamentalmente de los desafios a las transformaciones de la Argentina en el futuro. Para ello hemos identificado tres grandes momentos históricos en nuestro país donde se constituyeron los dos grandes "arreglos sociales" que sentaron las bases de la desigualdad socialmente aceptada por parte del conjunto de la sociedad. Identificamos el primero luego del proceso de sustitución de importaciones y el advenimiento del peronismo que consolidó las bases de nuestra "ciudadanía pampeana", que consistió en un arreglo social muy beneficioso para el sector del trabajo formal. El otro momento fue luego del proceso que denominamos "solución armada" impulsada por los sectores del capital ante su descontento por el peso de la ciudadanía pampeana, que impuso el neoliberalismo económico sentando las bases para la consolidación de un nuevo esquema de desigualdad beneficiosa para el capital. Finalmente identificamos un tercer 
momento que transcurrió a partir de la crisis del 2001 donde identificamos una nueva crisis del arreglo social que llevó a un reacomodamiento de la situación social destacando mejoras sustanciales en favor de los sectores populares pero aún con cambios estructurales bastante limitados. Aunque consideramos que se ha buscado (por ahora fallidamente) lograr reconstruir la vieja ciudadanía pampeana, creemos que en ese camino, y esa es la hipótesis del artículo, la AUH fue la política social más importante porque es la que generó un cambio de las lógicas que se venían aplicando. La AUH dejó de lado el modelo de políticas sociales focalizadas centradas en solucionar la pobreza de sectores puntuales generando un vínculo de caridad más que de derecho, para pasar a un modelo integral y más complejo que buscó darle continuidad al esquema de asignaciones familiares centrado en el enfoque de trabajo de las políticas sociales; esto es, el esquema de protección social asociado a la condición de trabajador. A su vez consideramos que esta política social ha dado el puntapié inicial en enfrentar el desafio ulterior de construcción de una nueva ciudadanía pampeana en el nuevo milenio, que necesitará forzar al sector capital al doble desafio de aumentar la generación y la distribución de excedente; se necesitan ambas cosas para lograr el objetivo final de aquella batalla que inició la lógica que estructuró la AUH.

Hace casi un año, el 10 de diciembre pasado, asumió un nuevo gobierno, considerado el primero de derecha que asume democráticamente. El nuevo presidente Mauricio Macri, de perfil neoliberal, viene impulsando políticas públicas contrarias a propiciar la protección de la industria nacional y garantizar pleno empleo y niveles de formalización laboral crecientes complicando fuertemente la posibilidad de avanzar hacia una nueva ciudadanía pampeana. En este sentido si bien durante todo el artículo hemos mencionado lo que el Estado ha realizado y discutimos sobre la orientación de esas decisiones, sin embargo un actor importante también es la propia ciudadanía. En este escenario de un gobierno de derecha en el poder que si bien ha prometido sostener la $\mathrm{AUH}$, no ha profundizado políticas orientadas en lo que es el objetivo esencial de esta política pública, que es tratar de generar las condiciones de pleno empleo formal, sino todo lo contrario. En este sentido creemos que será responsabilidad de la ciudadanía definir cuánta desigualdad es socialmente aceptable, si aceptamos lo dado, nos conformamos con la situación actual e incluso aceptamos empeorar y así ser parte de una nueva "ciudadanía irresponsable", o en cambio si no toleramos estar peor, si castigamos cualquier retroceso con organización popular, participación en protestas, sindicalización y obviamente también en el acto electoral. Si tomamos la segunda opción seguramente, incluso bajo un gobierno neoliberal, estaremos construyendo de una u otra manera la ciudadanía pampeana.

Lamentablemente por la extensión de este artículo no vamos a poder abordar las posibles estrategias, caminos, rutas a seguir de acá en adelante en este nuevo escenario donde la ciudadanía será la protagonista, pampeana o irresponsable. Escribir sobre ello será tarea de futuros trabajos que deberán aportar a este enorme desafio que es la construcción de una nueva ciudadanía pampeana en Argentina que garantice una sociedad más justa, igualitaria y por qué no decirlo, responsable.
1 Según el informe -"Panorama Social de América Latina 2011" de la Cepal la Argentina disminuyó el nivel de pobreza en 36 puntos porcentuales durante el período $2002-2010$, cayendo de $45,4 \%$ en 2002 a $8,6 \%$ en 2010.Ver en http://repositorio.cepal.org/handle/11362/124

$2 \mathrm{El}$ par categorial trabajo se refiere a las desigualdades propias dentro del sector del trabajo, a saber sectores formales, informales y desocupados.

3 Por ejemplo Mazzola (2012); Hintze (2015)

4 Es por ello que Franco plantea que las sociedades andinas tienen en ese patrón de articulación, rasgos particulares distintivos de los modelos europeos (Franco, 1997).

(6) Perú entre 1968 y 1975.

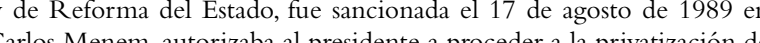
un gran número de empress estatales y a lusion y disolución de diversos entes públicos.

7 El frente electoral "Argentinos por una República de Iguales" (ARI) fue creado por un grupo de políticos -entre ellos Elisa Carrió- disidentes de la Alianza para el Trabajo, la Justicia y la Educación, coalición oficialista del gobierno presidido por Fernando de la Rúa 


\section{Referencias}

Barbeito, Alberto y Lo Vuolo, Rubén (2003) "El ingreso ciudadano en la agenda de políticas públicas de la Argentina" [en línea]. Disponible en Web:http://www.ingresociudadano.com.ar/index.php/home/menubrevehistoria [Consulta 18 de febrero de 2016]

Cortés, Rosalía y Gabriel Kessler (2013) "Miradas sobre la cuestión social en la Argentina democrática (1983-2013)". Cuestiones de Sociología 9 www.memoria.fahce. unlp.edu.ar/art_revistas/pr.5869/pd

Danani, Claudia (2009) "La Gestión de la política social: Un intento de aportar a su problematización". En Gestión de la política social. Conceptos y Herramientas Buenos Aires: Prometeo Libros, pp. 25-51

Dubet, François (2012) "Los límites de la igualdad de oportunidades". Nueva Sociedad 239:42-50.

Franco, Carlos (1996) "Desigualdad social, cultura de la desigualdad y representación democrática. Cuatro notas para el debate”. Socialismo y Participación 75:58-91.

Franco, Carlos (1997) “Ciudadanía plebeya y organizaciones sociales en el Perú (Otro camino para "otra" democracia)", en G. de SIERRA, dir, Democracia emergente en América del Sur. México: UNAM: 95-120.

Fraser, Nancy \& Linda Gordon (1992) "Contract vs. Charity: Why is there no Social Citizenship in the United States"? Socialist Review 22:45-68.

García Linera, Álvaro (2015) “La potencia plebeya: acción colectiva e identidades indígenas, obreras y populares en Bolivia”. Buenos Aires: CLACSO.

Hintze, Susana (2015) "La Asignación Universal por Hijo en el marco de la política y la seguridad social en Argentina”. Debate Público. Reflexión de Trabajo Social Año 5 Nº 9 pp. 57-67.

Mazzola, Roxana (2012) Nuevo paradigma: la asignación universal por hijo en la Argentina". Buenos Aires: Prometeo Libros.

Pérez Ledesma, Manuel (1998) "Ciudadanía Política y ciudadanía social: Los cambios de fin de siglo”. Studia histórica. Historia contemporánea No 16 pp. 35-65.

Pérez Sáinz y Minor Mora Salas (2009) “Excedente económico y persistencia de las desigualdades en América Latina”. Revista Mexicana de SociologíaVol. 71 N³, págs. 411-451.
Procacci, Giovanna (1999), "Ciudadanos pobres, la ciudadanía social y la crisis de los Estados de bienestar”, en S. García y S. Lukes (comps.), Ciudadanía: justicia social, identidad y participación, Madrid, Siglo XXI, pp. 15-44.

Repetto, Fabián (2010) "Hacia un sistema integral de protección social en Argentina: Algunos retos políticos y administrativos". Ponencia en el V Coloquio Local, III Regional y el II Foro de Economía Social "Economía Social /Desarrollo Local: una tensión a develar en la construcción del buen vivir". Santa Fe. Universidad Nacional del Litoral, pp. 66-88.

Soldano, Daniela y Luciano Andrenacci (2006) "Aproximación a las teorías de la política social a partir del caso argentino", en Problemas de política social en la Argentina contemporánea. Buenos Aires, UNGS-Editorial Prometeo.

Vilas, Carlos M. (1997)’De ambulancias, bomberos y policías: La política social del neoliberalismo (Notas para una perspectiva macro)”.Desarrollo Económico144:931-952.

\section{Cómo citar este artículo}

Currá, Nahuel (2017) : "Los desafíos de una nueva ciudadanía pampeana.

Consecuencias de la implementación de la Asignación Universal por Hijo (2009-2015)". Revista Perspectivas de Políticas Públicas vol. 6 № 12:369-393. 